\title{
HDlive Flow for Diagnosis of Invasive Mole
}

\author{
${ }^{1}$ Tomoya Yamashita, ${ }^{2}$ Chiaki Tenkumo, ${ }^{3}$ Megumi Ishibashi, ${ }^{4}$ Kenta Yamamoto, ${ }^{5}$ Nobuhiro Mori, \\ ${ }^{6}$ Kenji Kanenishi, ${ }^{7}$ Toshiyuki Hata
}

\begin{abstract}
Our experience of using HDlive flow or HDlive flow silhouette to diagnose invasive moles is presented. In the first case, a large ill-defined hypervascular mass occupying the entirety of fundal and anterior lesions of the uterus was identified using HDlive flow silhouette. The patient was successfully treated with methotrexate. In the second case, a circumscribed hypervascular tumor of the uterus was identified with HDlive flow. This patient was refractory to methotrexate and actinomycin-D and was successfully treated with etoposide, methotrexate, actinomycin D, cyclophosphamide, vincristine (EMA/CO). Based on ultrasound features, the difference in drug susceptibility between chemosensitive and refractory invasive moles may be due to the vascularity of the mass in the uterus.
\end{abstract}

Keywords: HDlive flow, HDlive flow silhouette, HDlive silhouette inversion mode, Invasive mole, Radiant flow.

How to cite this article: Yamashita T, Tenkumo C, Ishibashi M, Yamamoto K, Mori N, Kanenishi K, Hata T. HDlive Flow for Diagnosis of Invasive Mole. Donald School J Ultrasound Obstet Gynecol 2019;13(1):1-3.

Source of support: Nil

Conflict of interest: None

\section{INTRODUCTION}

With respect to conventional ultrasound images of invasive moles, two-dimensional (2D) sonographic features are heterogeneously solid or cystic-solid masses with an unclear border, and color/power Doppler findings are signal spots distributed within the boundary of tumors or throughout the whole tumors ("non-peripheral Doppler signal"). ${ }^{1}$ However, we cannot evaluate the exact location and spread of the mass in the uterus using conventional ultrasound.

The novel HDlive flow three-dimensional (3D) color / power Doppler, HDlive flow with its adjustable light source facilitates spatial reconstruction of the fetal heart and associated vessels and the vascularity of tumors in gynecologic diseases. ${ }^{2-7}$ The novel features of HDlive

\footnotetext{
${ }^{1}$ Resident, ${ }^{2,3}$ Assistant Professor, ${ }^{4}$ Senior Resident, ${ }^{5}$ Lecturer,

${ }^{6}$ Associate Professor, ${ }^{7}$ Professor and Chairman

${ }^{1-7}$ Department of Perinatology and Gynecology, Kagawa University, Graduate School of Medicine, Kagawa, Japan

Corresponding Author:Toshiyuki Hata, Professor and Chairman, Department of Perinatology and Gynecology, Kagawa University, Graduate School of Medicine, Kagawa, Japan, Phone: +81-(0)87-891-2174, e-mail: toshi28@med. kagawa-u.ac.jp
}

flow silhouette allow operators to distinguish between overlapping blood vessels and comprehend spatial relationships that exist among blood vessels and their surrounding structures. ${ }^{8-11}$ To our best knowledge, no studies have been conducted on the HDlive flow or HDlive flow silhouette-based findings of an invasive mole. The present aim was to describe our experience of invasive mole diagnosis based on HDlive flow or HDlive flow silhouette.

\section{Case 1}

The patient was a 34-year-old Japanese woman, gravida 1 , para 0 , who had been referred to our hospital because the anechogenic mass had been identified in the uterus with continuously high hCG levels in the serum. Dilatation and curettage due to early first-trimester missed abortion had been conducted19 weeks previously. A partial hydatidiform mole was diagnosed pathologically. The level of serum hCG was $219.7 \mathrm{mIU} / \mathrm{mL}$. We conducted transvaginal 2D sonography, revealing an ill-defined, inhomogeneous lesion with small hypoechoic cysts of diverse sizes throughout the anterior myometrium (Fig. 1A). Transvaginal radiant flow subsequently identified a hypervascular lesion throughout the anterior myometrium (Fig. 1B). Then, HDlive flow silhouette (Voluson E10, GE Healthcare Japan, Tokyo, Japan) revealed a largesized hypervascular mass throughout the fundal and anterior uterine lesions (Figs 1C and D). Also, the spatial location of the mass could be clearly recognized. The MRIbased diagnosis was also an invasive mole. No metastasis was noted on CT. FIGO 2000 system assessment was stage I:2. Three courses of methotrexate administration were performed. After treatment, the serum hCG level normalized, and the uterine echogenic mass disappeared.

\section{Case 2}

The patient was a 31-year-old Japanese woman, gravida 1 , para 0 , who had been referred to our hospital because the anechogenic mass had been identified in the uterus with continuously high serum hCG levels. Dilatation and curettage due to early first-trimester missed abortion had been conducted 7 weeks previously. A complete hydatidiform mole was diagnosed pathologically. The level of serum hCG was $82.113 \mathrm{mIU} / \mathrm{mL}$. We conducted transvaginal 2D sonography, revealing a well-defined 


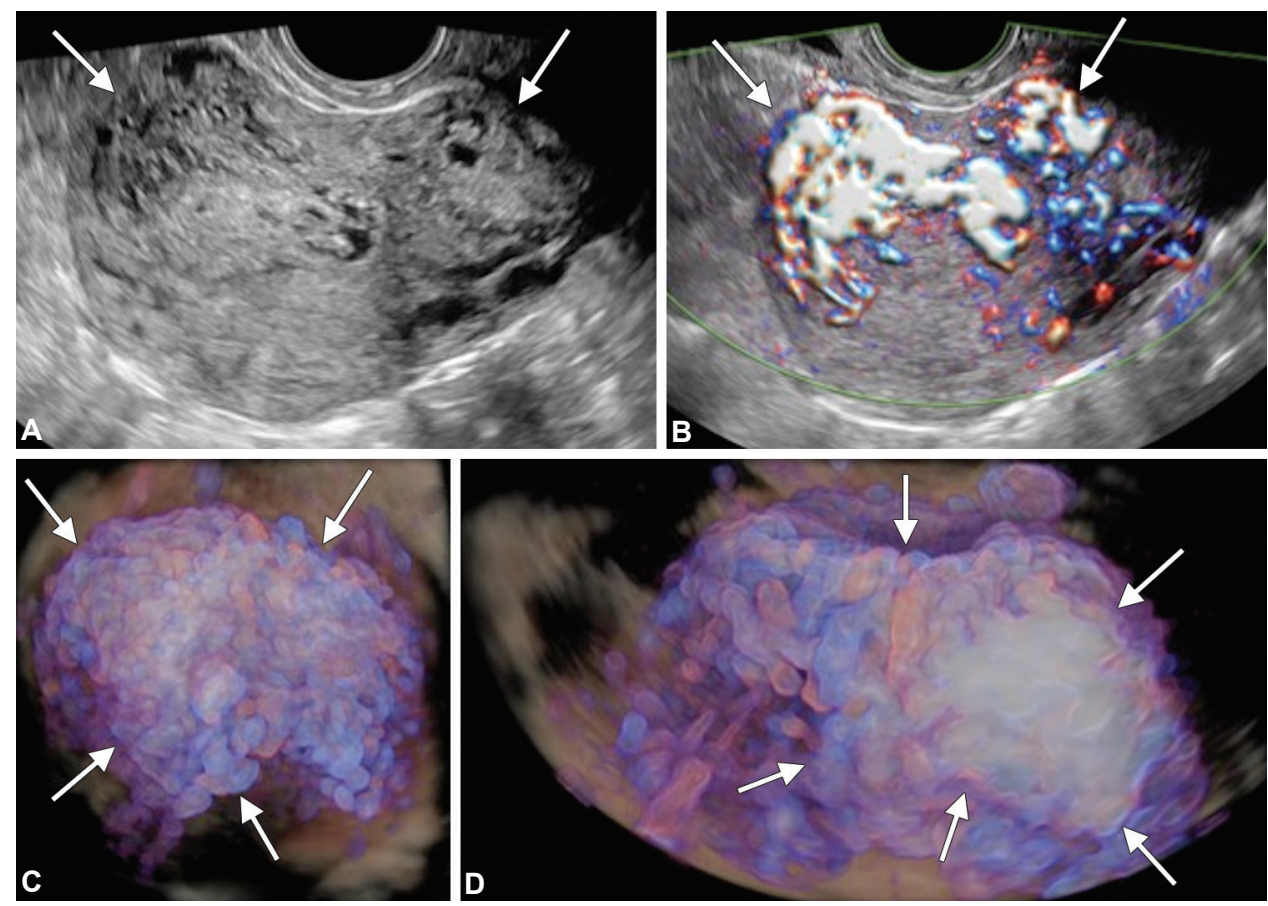

Figs $1 \mathrm{~A}$ to D: Chemosensitive invasive mole. The use of transvaginal two-dimensional sonography reveals an ill-defined, inhomogeneous lesion with small hypoechoic cysts of various sizes (arrows) throughout the anterior myometrium. (A) Transvaginal radiant flow reveals a hypervascular lesion (arrows) throughout the anterior myometrium; (B) The use of HDlive flow silhouette reveals a large hypervascular mass (arrows) throughout the fundal and anterior uterine lesions; (C and D) The position of the mass is clear; (C) Anterior view; (D) Superior view
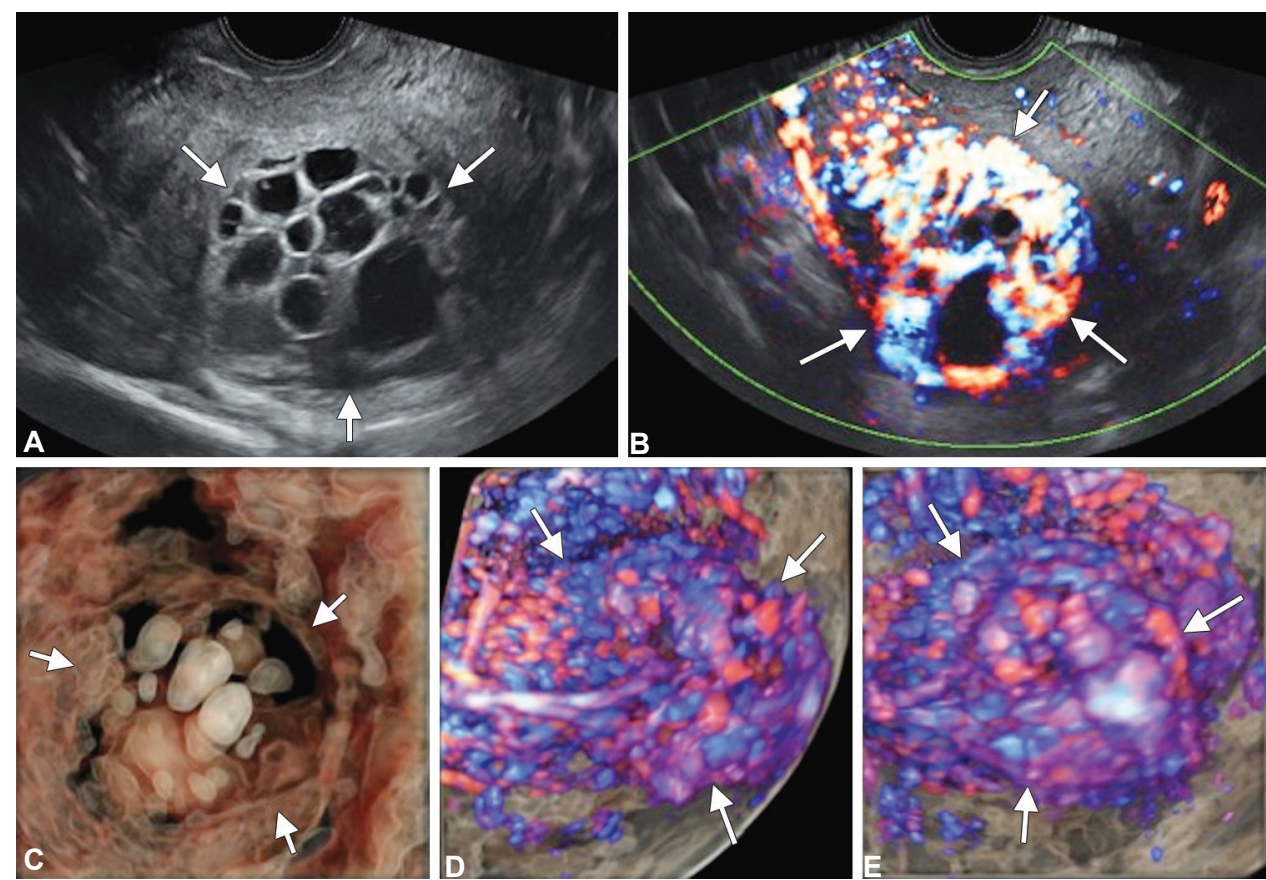

Figs 2A to E: Chemorefractory invasive mole. The use of transvaginal two-dimensional sonography reveals a well-defined echogenic mass with many large cysts within the posterior uterine wall (arrows). (A) Abundant blood flow around the cysts inside the mass (arrows) was identified using color Doppler; (B) HDlive silhouette inversion mode depicts many thick-walled cysts (arrows); (C) HDlive flow shows a well-circumscribed uterine hypervascular tumor (mirror-ball appearance); (D and E) Frontal view and lateral view

echogenic mass with many large cysts in the posterior uterine wall (Fig. 2A). Abundant blood flow around the cysts inside the mass was noted on color Doppler (Fig. 2B). There were numerous cysts with thick walls using the HDlive silhouette inversion mode (Fig. 2C). The circumscribed uterine hypervascular tumor (mirror-ball appearance) was clearly shown by HDlive flow (Figs 2D and E). CT ruled out the presence of metastasis. FIGO 2000 system assessment was stage I:4. This patient was refractory to methotrexate and actinomycin-D and was successfully treated with EMA/CO (etoposide + methotrexate + actinomycin-D/cyclophosphamide + vincristine). 


\section{DISCUSSION}

For gestational trophoblastic neoplasia (GTN) classed as nonmetastatic (stage I) or low-risk metastatic (stages II and III, score $<7$ ), a survival rate close to $100 \%$ can be achieved with single-agent chemotherapy. ${ }^{12}$ The overall response rate without recurrence was $64.6-91.5 \%$ for firstline treatment. ${ }^{13,14}$ However, it is still difficult to predict or differentiate which of nonmetastatic or low-risk metastatic GTN will relapse or be chemorefractory to methotrexate. ${ }^{15}$ In the present study, the HDlive flow silhouette characteristics of a chemosensitive invasive mole were an ill-defined mass with abundant blood flow, whereas the HDlive flow characteristic of a chemorefractory invasive mole was a fairly well-defined mass including numerous cysts inside the mass with abundant blood flow. Also, using HDlive flow or its silhouette we could comprehend the spatial relationships of overlapping blood vessels within a hypervascular invasive mole. To the best of our knowledge, this is the first study to describe the characteristic vascular patterns of chemosensitive and chemoresistant invasive moles using HDlive flow or HDlive flow silhouette. Therefore, the difference in drug-susceptibility between chemosensitive and chemorefractory invasive moles may be due to the vascularity of the mass in the uterus. However, such vascular patterns should be viewed with caution due to the limited number of subjects studied. Future studies with larger sample sizes are needed to confirm the applicability of this technique diagnose and assess the drug-susceptibility of an invasive mole.

\section{REFERENCES}

1. Qin J, Ying W, Cheng X, et al. A well-circumscribed border with peripheral Doppler signal in sonographic image distinguishes epithelioid trophoblastic tumor from other gestational trophoblastic neoplasms. PLoS One 2014;9(11):e112618.

2. AboEllail MAM, Kanenishi K, Tenkumo C, et al. Diagnosis of trncus arteriosus in the first trimester of pregnancy using four-dimensional color Doppler ultrasound. Ultrasound Obstet Gynecol 2015;45:759-760.
3. Yamamoto K, AboEllail MAM, Ito M, et al. HDlive imaging in diagnosis of uterine artery pseudoaneurysm during pregnancy. Ultrasound Obstet Gynecol 2016;48:125-128.

4. Sajapala S, AboEllail MAM, Tanaka T, et al. Three-dimensional power Doppler with silhouette mode for diagnosis of malignant ovarian tumors. Ultrasound Obstet Gynecol 2016;48:806-808.

5. AboEllail MAM, Ishimura M, Sajapala S, et al. Threedimensional color/power Doppler sonography and HDlive silhouette mode for diagnosis of molar pregnancy. J Ultrasound Med 2016;35:2049-2052.

6. Tenkumo C, Hanaoka U, AboEllail MAM, et al. HDlive Flow with HDlive silhouette mode in diagnosis of fetal hepatic hemangioma. Ultrasound Obstet Gynecol 2017;49:540-545.

7. Yamamoto K, AboEllail MAM, Ishimura M, et al. HDlive silhouette inversion mode in diagnosis of complete hydatidiform mole. J Ultrasound Med 2017;36:833-835.

8. Ito M, AboEllail MAM, Yamamoto K, et al. HDliveFlow with spatiotemporal image correlation for the diagnosis of congenital heart disease. Ultrasound Obstet Gynecol 2017;50:411-415.

9. Hata T, Kanenishi K, Tanaka T, et al. HDliveFlow silhouette mode for the diagnosis of uterine sarcoma. Donald School J Ultrasound Obstet Gynecol 2017;11:259-260.

10. Tenkumo C, Kanenishi K, AboEllail MAM, et al. HDliveFlow silhouette mode for the diagnosis of uterine enhanced myometrial vascularity/arteriovenous malformations. J Med Ultrasonics 2018;45:349-352.

11. Hata T, Kanenishi K, Nitta E, et al. HDliveFlow silhouette mode with HDlive silhouette mode for diagnosis of molar pregnancy. Ultrasound Obstet Gynecol 2018;52:552-554.

12. Lurain JR. Gestational trophoblastic disease II: classification and management of gestational trophoblastic neoplasia. Am J Obstet Gynecol 2011;204:11-18.

13. Khan F, Everard J, Ahmed S, et al. Low-risk persistent gestational trophoblastic disease treated with low-dose methotrexate: efficacy, acute and long-term effects. Br J Cancer 2003;89:2197-2201.

14. Foulmann K, Guastalla JP, Caminet N, et al. What is the best protocol of single-agent methotrexate chemotherapy in nonmetastatic or low-risk metastatic gestational trophoblastic tumors? A review of the evidence. Gynecol Oncol 2006;102: 103-110.

15. Powles T, Savage PM, Stebbling J, et al. A comparison of patients with relapsed and chemo-refractory gestational trophoblastic neoplasia. Br J Cancer 2007;96:732-737. 